\title{
PENERAPAN PEMBELAJARAN MULTIMEDIA SEBAGAI INOVASI PEMBELAJARAN PADA TK PKK KALITIRTO BERBAH
}

\section{Application Of Multimedia Learning As A Learning Innovation In PKK Kindergarten Kalitirto Berbah}

\author{
Rizqi Sukma Kharisma \\ Fakultas Ilmu Komputer Universitas Amikom Yogyakarta \\ sukma@amikom.ac.id
}

\begin{abstract}
ABSTRAK
Teknologi informasi sudah merambah ke semua lini kehidupan baik untuk kebutuhan ekonomi, kemasyarakatan dan pendidikan. Di sektor pendidikan teknologi dugunakan untuk kebutuhan menunjang proses belajar mengajar dan juga digunakan untuk manajemen sekolah.

TK PKK Kalitirto merupakan salah satu tempat pendidikan usia dini yang berada di wilayah kecamatan Berbah, kabupaten Sleman. Dengan pesatnya perkembangan teknologi saat ini, TK PKK Kalitirto masih cukup tertinggal dari segi fasilitas yang digunakan. Pada sisi kegiatan belajar mengajar TK PKK Kalitirto juga ingin memiliki media pembelajaran multimedia di samping media pembelajaran manual yang sudah ada. Namun dengan keterbatasan anggaran dana yang di mana rata-rata orang tua siswa TK PKK Kalitirtio merupakan kelas ekonomi menengah ke bawah, pengadaan media pembelajaran multimedia ini dirasa cukup sulit.

Dari permasalah tersebut di atas maka dalam Pengabdian ini dilaksanakan penyediaan fasilitas media pembelajaran yang berbasis multimedia dan pelatihan dalam penggunaannya. Diharapkan guru-guru TK PKK Kalitirto dapat secara mandiri menggunakan media pembelajaran multimedia yang ada untuk kegiatan belajarmengajar.
\end{abstract}

Kata Kunci : media pembelajaran, multimedia, taman kanak-kanak

\section{ABSTRACT}

Information technology has penetrated into all lines of life both for economic, social and educational needs. In the education sector technology is used for the needs of supporting the teaching and learning process and also used for school management.

PKK Kindergarten Kalitirto is one of the places for early education in the Berbah sub-district, Sleman district. With the rapid development of technology at this time, PKK Kindergarten Kalitirto is still quite behind in terms of the facilities used. On the teaching and learning activities PKK Kindergarten Kalitirto also wants to have multimedia learning in addition to the existing manual learning media. However, due to budget constraints where the average parents of Kalitirtio PKK Kindergarten students are in the middle to lower economic class, the procurement of multimedia learning is considered quite difficult.

From the problems mentioned above, in this service the provision of multimedia-based learning facilities and training in their use are carried out. It is hoped that PKK Kindergarten Kalitirto teachers can independently use existing multimedia learning for teaching and learning activities.

Keywords : learning media, multimedia, kindergarten

\section{PENDAHULUAN}

Ditulis dengan jelas menggunakan huruf times new roman font 11 spasi 1

\section{Analisis Situasi}

Menurut Peraturan Menteri Pendidikan

Dan Kebudayaan Republik Ind onesia Nomor

84 Tahun 2014 pasal 1 ayat 4, Taman Kanak- kanak yang selanjutnya disingkat TK adalah salah satu bentuk satuan PAUD pada jalur pendidikan formal yang menyelenggarakan program pendidikan bagi anak berusia 4 (empat) tahun sampai dengan 6 (enam) tahun dengan prioritas usia 5 (lima) dan 6 (enam) tahun. (Kementrian Pendidikan dan Kebudayaan, 2015) 
TK PKK Kalitirto merupakan sebuah TK yang beralamatkan di Jl. Berbah Kalasan, dusun Sumber Lor, kelurahan Kalitirto, Kecamatan Berbah, kabupaten Sleman. TK ini memiliki potensi untuk berkembang dengan didukung dengan penilaian akreditasi yang telah didapat yaitu akreditasi B. Jumlah siswa TK PKK Kalitirto dari tahun ke tahun relatif stabil yang berasal dari keluarga ekonomi menengah ke bawah. Jumlah murid TK PKK Kalitirto disajikan pada Tabel 1 :

Tabel 1 Jumlah murid TK PKK Kalitirto

\section{No Tahun Kelompok A Kelompok B Jumlah}

\begin{tabular}{lllll}
\hline 1 & $2013 / 2014$ & 16 & 17 & 35 \\
\hline 2 & $2014 / 2015$ & 18 & 15 & 33 \\
\hline 3 & $2015 / 2016$ & 20 & 19 & 39 \\
\hline 4 & $2016 / 2017$ & 17 & 17 & 34 \\
\hline 5 & $2017 / 2018$ & 17 & 18 & 35 \\
\hline 6 & $2018 / 2019$ & 17 & 17 & 34 \\
\hline
\end{tabular}

Namun jumlah pengajar dan staff administrasi tidak proporsional, bahkan guru kelas juga merangkap sebagai staff

\begin{tabular}{ll}
\hline No Permasalahan & $\begin{array}{l}\text { Luaran Sebagai } \\
\text { Solusi Masalah } \\
\text { Mitra }\end{array}$ \\
\hline
\end{tabular}

Kegiatan belajar mengajar diakukan secara konvensional menggunakan alat

1 peraga manual, sering guru-guru mengalami kesulitan untuk menampilkan materimateri tertentu kepada siswa

\begin{tabular}{|c|c|c|}
\hline 2 & $\begin{array}{l}\text { Pemahaman pengunaan } \\
\text { teknologi informasi } \\
\text { rendah bagi Guru dan } \\
\text { Staff mitra }\end{array}$ & $\begin{array}{l}\text { Pelatihan } \\
\text { teknologi } \\
\text { informasi dan } \\
\text { penggunaan media } \\
\text { pembelajaran } \\
\text { multimedia }\end{array}$ \\
\hline \multicolumn{3}{|c|}{$\begin{array}{l}\text { administrasi dan kebersihan. Hanya terapat } 4 \\
\text { orang personil dalam TK PKK Kalitirto yang } \\
\text { disajikan pada Tabel } 2 \text { : }\end{array}$} \\
\hline
\end{tabular}

Tabel 2 Jumlah Guru dan Staff TK PKK Kalitirto

\begin{tabular}{|c|c|c|}
\hline No & Nama & Jabatan \\
\hline 1 & Ani Susianti, SPd AUD & $\begin{array}{c}\text { Kepala Sekolah / } \\
\text { Guru } \\
\text { Kelas } \\
\end{array}$ \\
\hline 2 & Marpujiwati, S.Pd AUD & Guru Kelas \\
\hline 3 & Sri Mujiati, S.Pd AUD & Guru Kelas \\
\hline 4 & $\begin{array}{l}\text { Niken Hastrini } \\
\text { Setyaningrum, SH }\end{array}$ & Guru Kelas \\
\hline 5 & Satinem & Tenaga Kebersihan \\
\hline
\end{tabular}

Kegiatan belajar mengajar di TK PKK Kalitirto hanya dilakukan dengan menggunakan alat peraga manual. Padahal kebutuhan teknologi informasi multimedia dapat membantu proses belajar mengajar (Wibawanto, 2017). Menurut kepala sekolah TK PKK Kalitirto Ani Susianti, SPd AUD, sekolah ingin memiliki media pembelajaran berbasis multimedia yang juga mendukung kegiatan belajar mengajar. Hal ini juge merupakan tuntutan perubahan zaman di mana media pembelajaran tidak hanya menggunakan alat peraga manual tapi juga menggunakan media pembelajaran multimedia. Dengan keterbatasan pengetahuan dan fasilitas yang ada, media pembelajaran multimedia yang diinginkan belum dapat terrealisasi.

\section{Permasalahan Mitra}

Setelah melakukan observasi dan wawancara dengan calon mitra yaitu TK PKK Kalitirto serta pengamatan langsung di lapangan didapatkan beberapa permasalahan. Permasalahan-permasalahan tersebut kemudian didiskusikan dengan calon mitra dan mendapatkan kesepakatan prioritas permasalahan yang disajikan pada tabel 3 sebagai berikut :

Tabel 3. Daftar Permasalahan dan Luaran Sebagai Solusi Masalah pada TK PKK Kalitirto

\section{METODE}

Adapun metode pelaksanaan kegiatan pengabdian di TK PKK Kalitirto adalah sebagai berikut : 
a) Menganalisa kebutuhan dan pengambilan data

b) Dalam tahapan ini, pengusul melakukan analisa kebutuhan-kebutuhan untuk mengatasi permasalahan yang ada pada TK PKK Kalitirto. Melibatkan guru dan kepala sekolah TK PKK Kalitirto untuk menyampaikan kebutuhan- kebutuhan yang ada.

c) Melakukan pemaparan tentang pentingnya teknologi informasi

d) Dalam tahapan ini pengusul memaparkan dan mengedukasi tentang pentingnya teknologi informasi untuk proses belajar mengajar Melibatkan guru dan kepala sekolah TK PKK Kalitirto.

e) Pelatihan dan penggunaan media pembelajaran multimedia

f) Dalam tahapan ini pengusul mengadakan pelatihan dan penggunaan media pembelajaran multimedia kepada guru dan kepala sekolah TK PKK Kalitirto. Tidak hanya dalam penggunaan, tapi pengusul juga mengajarkan bagaimana perawatan perangkat-perangkat multimedia yang ada agar dapat terus digunakan.

g) Pendampingan sekaligus evaluasi setelah pelatihan

h) Dalam tahapan ini pengusul melakukan evaluasi kegiatan dan pendampingan setelah pelatihan dan setelah PKM berlangsung. Hal ini untuk memastikan agar guru dan kepala sekolah TK PKK Kalitirto mandiri dalam menggunakan dan perangkat-perangkat multimedia yang ada.

Adapun detil metode pelaksanaan disampaikan pada tabel 4 :

Tabel 4. Detil Metode Pelaksanaan

\begin{tabular}{|c|c|c|}
\hline No & Permasalahan & Metode Pelaksanaan \\
\hline 1 & $\begin{array}{l}\text { Kegiatan belajar } \\
\text { mengajar diakukan } \\
\text { secara } \\
\text { konvensional } \\
\text { menggunakan alat } \\
\text { peraga manual, } \\
\text { sering guru-guru } \\
\text { mengalami } \\
\text { kesulitan untuk }\end{array}$ & $\begin{array}{ll}\text { 1. } & \text { Menyediakan } \\
\text { perangkat monitor, } \\
\text { Set Top Box (STB) } \\
\text { Android, Penyediaan } \\
\text { Media Pembelajaran } \\
\text { Multimedia. } \\
\text { 2. } \\
\text { Mitra memberikan } \\
\text { masukan silabus } \\
\text { untuk mendukung } \\
\text { pembuatan media } \\
\text { pembelajaran }\end{array}$ \\
\hline
\end{tabular}

\begin{tabular}{lll}
\hline menampilkan & multimedia. \\
materi-materi & 3. & $\begin{array}{l}\text { Pembuatan buku } \\
\text { manual petunjuk } \\
\text { tertentu kepada }\end{array}$ \\
siswa & $\begin{array}{l}\text { penggunaan media } \\
\text { pembelajaran } \\
\text { multimedia }\end{array}$ \\
& 1. & Pelatihan teknologi \\
& informasi dan \\
& penggunaan media \\
& pembelajaran \\
Pemahaman & multimedia serta \\
pengunaan & perawatan prangkat \\
teknologi & yang ada. \\
informasi rendah & Mitra mengikuti \\
bagi Guru dan & pelatihan dan parktik \\
Staff mitra & pengguna media \\
& pembelajaran \\
& multimedia.
\end{tabular}

\section{HASIL DAN PEMBAHASAN \\ HASIL \\ Melakukan Pemaparan Tentang Pentingnya Teknologi Informasi}

Dalam tahapan ini pengusul memaparkan dan mengedukasi tentang pentingnya teknologi informasi untuk proses belajar mengajar Melibatkan guru dan kepala sekolah TK PKK Kalitirto. Teknologi yang akan di tranver ini merupakan media pembelajaran multimedia.

\section{Pelatihan Dan Penggunaan Media Pembelajaran Multimedia}

Dalam tahapan ini pengusul mengadakan pelatihan dan penggunaan media pembelajaran multimedia kepada guru dan kepala sekolah TK PKK Kalitirto. Tidak hanya dalam penggunaan, tapi pengusul juga mengajarkan bagaimana perawatan perangkat-perangkat multimedia yang ada agar dapat terus digunakan. Pada gambar 4 guru-guru sedang mengikuti pelatihan.

Dalam pengabdian ini diserahkan seperangkat media pembelajaran multi media berupa :

a) Perangkat Set Top Box (STB) Android yang di dalamnya telah terinstall media pembelajaran. Gambar 6 dan Gambar 7 menujukkan media pembelajaran yang diinstal. 
b) Proyektor yang digunakan untuk perangkat menampilkan media pembelajaran

c) Speaker

d) Mouse nirkabel

\section{KESIMPULAN}

Dari kegiatan pengabdian masyarakat pada TK PKK Kalitorto Berbah dapat disimpulkan sebagai berikut :

a) Pentingnya kesadaran dan kemampuan penggunaan media teknologi untuk proses belajar mengajar.

b) Media pembelajaran multimedia dapat membantu dalam proses inovasi belajar mengajar.

\section{SARAN}

Saran bagi pembaca untuk meneruskan kegiatan pengabdian pada TK PKK Kalitorto Berbah adalah : a) Penambahan perangkat koneksi internet untuk meaksimalkan perangkan media pembelajaran multimedia.

b) Pelatihan lanjutan untuk memaksimalkan penggunaan perangkan media pembelajaran multimedia.

c) Pelatihan manajemen pengelolan administrasi sekolah dengan menggunakan teknologi informasi.

\section{DAFTAR PUSTAKA}

Kementrian Pendidikan dan Kebudayaan. (2015). Retrieved Oktober 10, 2018, from http://paud.kemdikbud.go.id/wpcontent/uploads/2016/04/Permendikbud-84Tahun-2014.pdf

Wibawanto, W. (2017). Desain dan Pemrograman Multimedia Pembelajaran Interaktif. Jember: Penerbit Cerdas Ulet Kreatif. 